IFAS Extension

\title{
Datos sobre las vitaminas ${ }^{1}$
}

\author{
R. Elaine Turner y Wendy J. Dahl ${ }^{2}$
}

\section{¿Qué son las vitaminas?}

Las vitaminas son compuestos químicos que el cuerpo utiliza de muchas maneras. Nosotros necesitamos obtener las vitaminas en nuestra dieta porque nuestros cuerpos no las pueden crear. Existen 13 tipos de vitaminas que han sido identificadas como nutrientes importantes para los humanos.

\section{¿Cuáles son los diferentes tipos de vitaminas?}

Las vitaminas se dividen en dos grupos: solubles en agua y solubles en grasa. Las vitaminas solubles en agua son las vitamina $\mathrm{C}$ y $\mathrm{B}$. Las vitaminas solubles en grasa son las vitaminas $\mathrm{A}, \mathrm{D}, \mathrm{E}$ y $\mathrm{K}$.

Las vitaminas solubles en agua y las solubles en grasa se diferencian en la facilidad con que se disuelven en el agua. Esto afecta principalmente como los diferentes tipos de vitaminas se absorben y se transportan en el cuerpo. La mayoría de las vitaminas tienen un nombre químico y un nombre en letra.

\section{VITAMINAS SOLUBLES EN AGUA}

- Ácido Ascórbico (Vitamina C)

- Tiamina (Vitamina $\mathrm{B}_{1}$ )

- Riboflavina (Vitamina $\mathrm{B}_{2}$ )

- Niacina (Vitamina $\mathrm{B}_{3}$ )

- Piridoxina (Vitamina $\mathrm{B}_{6}$ )

- Cobalamina (Vitamina $\mathrm{B}_{12}$ )

- Folato

- Ácido Pantoténico

- Biotina

\section{VITAMINAS SOLUBLES EN GRASA}

- Retinol (Vitamina A)

- Calciferol (Vitamina D)

- Tocoferol (Vitamina E)

- Fitomenadiona (Vitamina K)

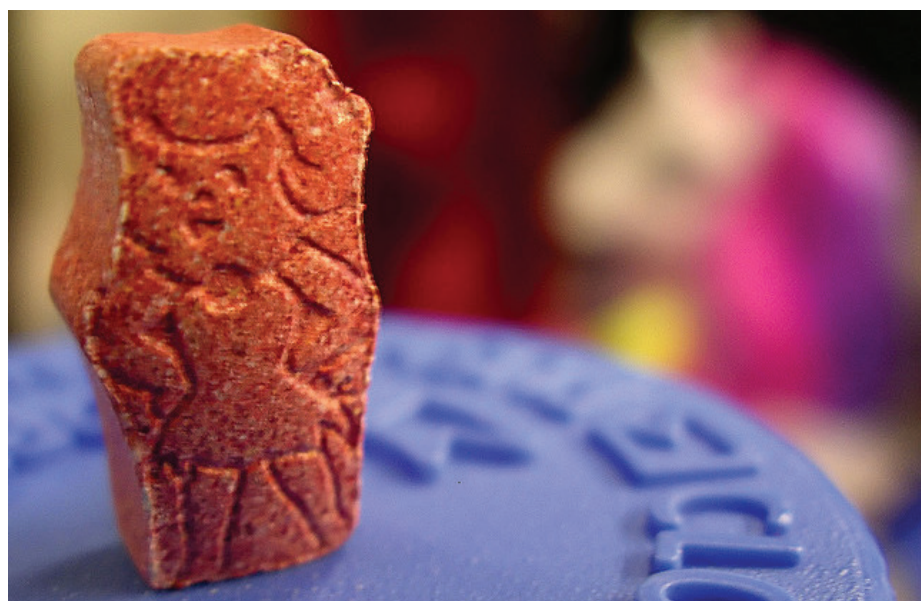

Figure 1. Vitamina masticable para niños - Muchos de nosotros podemos pensar de esta imagen icónica cuando pensamos acerca de las vitaminas, pero una dieta saludable realmente comienza con la elección de alimentos saludables.

Credits: Lisa Brewster. CC BY-SA 2.0. http://flic.kr/p/5CAsdv

\section{¿Cómo funcionan las vitaminas en el cuerpo?}

Las vitaminas trabajan en varias reacciones que regulan los procesos del cuerpo. La siguiente lista ofrece ejemplos de algunas vitaminas y sus funciones específicas.

1. The English version of this document is FCS8808/FY890 Facts About Vitamins. Este documento, FCS8808s, es uno de una serie de publicaciones del Departamento de Ciencias de la Familia, la Juventud y la Comunidad, Servicio de Extensión Cooperativa de la Florida, Instituto de Alimentos y Ciencias Agrícolas, Universidad de la Florida (UF/IFAS). Fecha de primera publicación noviembre de 2012. Visite EDIS en http://edis.ifas.ufl.edu/.

2. R. Elaine Turner, PhD, RD, profesora y decano asociada, College of Agricultural and Life Sciences; Wendy J. Dahl, PhD, RD, profesora asistente, Food Science and Human Nutrition Department, Universidad de la Florida, Gainesville, FL 32611. 
- Vitamina C, vitamina E y el beta-caroteno (una forma de la vitamina A) actúan como antioxidantes. Estas previenen que las células sean dañadas por el oxígeno.

- Vitamina A es importante para una visión normal y para la función inmune.

- Vitamina D es necesaria para la salud ósea.

- Vitamina K es importante para la coagulación de la sangre.

\section{¿Dónde encontramos las vitaminas en los alimentos?}

Todos los grupos de alimentos contienen alimentos ricos en vitaminas. La leche contiene riboflavina naturalmente y es fortificada con vitaminas A y D. Los granos enriquecidos contienen tiamina, riboflavina, niacina y ácido fólico añadido.

La vitamina $\mathrm{C}$ se encuentra en las frutas y los vegetales, mientras que los alimentos de origen animal sólo contienen vitamina $\mathrm{B}_{12}$ naturalmente. Algunos alimentos altos en grasas, como el aceite vegetal, aderezos para ensaladas, nueces, semillas y mayonesa son ricas en vitamina E. Es importante consumir una variedad de alimentos de cada grupo de alimentos para satisfacer los requisitos diarios.

Para obtener información acerca de los nutrientes que se encuentran en los diversos grupos de alimentos, vea ChooseMyPlate.gov o contacte su oficina de extensión local.

\section{¿Los alimentos frescos contienen más vitaminas?}

Las frutas frescas y los vegetales son fuentes buenas de distintos tipos de vitaminas. Mientras más frescas sean, mayor cantidad de vitaminas contienen. Los mercados de los agricultores son una excelente fuente de frutas y vegetales frescos de temporada.

Los productos enlatados, las frutas y los vegetales congelados pueden ser tan nutritivos como los productos frescos. Cuando el producto se enlata o se congela, es procesado rápidamente y sellado en un empaque para reducir la pérdida de vitaminas.

\section{¿Cómo puedo sacar el máximo provecho de los alimentos que consumo?}

Las vitaminas, especialmente las solubles en agua pueden ser reducidas en cantidad cuando el alimento es expuesto al calor, luz o aire. El cocinar los alimentos, especialmente si son cortados en trozos, cocinados por un período largo de tiempo y en grandes cantidades de agua, reduce el contenido vitamínico. Éstos son algunos consejos de cocina para ayudar a preservar el contenido vitamínico de sus alimentos:

- Utilice tan poca agua como pueda.

- Mantenga los trozos de alimentos tan grandes como se pueda.

- Cocine por poco tiempo.

- Microondas, salteados o al vapor cocinar las verduras.

- Utilice el agua con que se cocinaron los vegetales para hacer sopas o guisos (Utilice en un par de días, o congele).

\section{¿Cuánto de cada vitamina necesito por día?}

La cantidad de vitaminas que necesitamos por día es en realidad muy pequeña-mucho menor que las cantidades de carbohidratos, proteínas y grasas necesarias para una dieta saludable. Por ejemplo, nosotros necesitamos solo unos pocos microgramos de vitamina $B_{12}$ por día. Para darle una idea de cuan poco es, juna cucharadita de vitamina $B_{12}$ es suficiente para satisfacer los requisitos diarios de 2 millones de adultos!

El \% del valor diario (\%VD) de una vitamina en la etiqueta de los alimentos muestra el porcentaje de la necesidad diaria de un adulto normal saludable para esa vitamina y lo que ofrece el alimento por porción. Por ejemplo, un vaso de jugo de naranja proporciona $120 \%$ del valor diario de la vitamina C y $15 \%$ del valor diario de folato.

Tabla 1.

$100 \%$ Jugo de naranja -fortificado en calcio

Datos de Nutrición

Tamaño de la porción 8 ozfl $(240 \mathrm{ml})$

Porciones por envase 8

Cantidad por porción

Calorías 110

Calorías de grasa 0

$\%$ Valor Diario

Grasa Total 0g $0 \%$

Sodio 0mg

Potasio $450 \mathrm{mg}$

Carbohidratos totales $26 \mathrm{~g}$

Azúcares $22 \mathrm{~g}$

Proteína $2 \mathrm{~g}$

\begin{tabular}{|c|c|}
\hline Vitamina C $\mathbf{1 2 0} \%$ & Niacina $4 \%$ \\
\hline Calcio $35 \%$ & Vitamina $\mathrm{B}_{6} \mathbf{5 \%}$ \\
\hline Tiamina $10 \%$ & Folato $15 \%$ \\
\hline Riboflavina $6 \%$ & Magnesio $6 \%$ \\
\hline
\end{tabular}

No es una fuente significante de grasas saturadas, colesterol, fibra dietética, vitamina A o hierro.

*Valores porcentuales diarios basados en una dieta de 2,000 calorías. 


\section{¿Debería tomar suplementos para obtener las vitaminas que necesito?}

Es posible obtener todas las vitaminas que se necesitan mediante la selección de alimentos saludables, a veces las personas necesitan suplementos.

Por ejemplo, todas las mujeres en sus años prenatales deben tomar 400 microgramos de ácido fólico todos los días provenientes de alimentos enriquecidos o suplementos, además del folato en una dieta variada. Las mujeres en embarazo deben preguntar a su médico acerca de suplementos apropiados para ellas.

Los adultos mayores pueden tener dificultad para absorber la vitamina $\mathrm{B}_{12}$ de los alimentos. Los adultos mayores también necesitan más vitamina $\mathrm{D}$ a medida que envejecen. La mayor parte de su consumo de vitamina $B_{12}$ debería de provenir de alimentos fortificados o suplementos.

\section{¿Puede altas cantidades de vitaminas ser perjudiciales?}

Con las vitaminas, como con muchas cosas en la vida, más no significa que es necesariamente mejor. Algunas vitaminas pueden ser tóxicas en grandes cantidades (consulte la siguiente tabla). Los efectos secundarios van desde malestar estomacal o diarrea hasta un daño hepático o defectos de nacimiento.

Tabla 2.

\begin{tabular}{|l|l|}
\hline \multicolumn{2}{|c|}{$\begin{array}{c}\text { Máximo consumo sugerido } \\
\text { ¡No consuma más de estas cantidades! }\end{array}$} \\
\hline Niacina & $35 \mathrm{mg}$ (de suplementos) \\
\hline Vitamina $\mathrm{B}_{6}$ & $100 \mathrm{mg}$ (de suplementos) \\
\hline Folato & $1,000 \mathrm{mcg}$ (como ácido fólico) \\
\hline Vitamina C & $2,000 \mathrm{mg}$ \\
\hline Vitamina A & $3,000 \mathrm{mcg}(10,000 \mathrm{IU})$ \\
\hline Vitamina D & $50 \mathrm{mcg}(2,000 \mathrm{IU})$ \\
\hline Vitamina E & $1,000 \mathrm{mg}(1,500 \mathrm{IU})$ \\
\hline $\begin{array}{l}\text { mg = miligramos } \\
\text { mcg = microgramos } \\
\text { IU = Unidades Internacionales }\end{array}$ \\
\hline
\end{tabular}

El consumo excesivo de las vitaminas por lo general proviene de altas dosis de suplementos. Es por esta razón que las personas no deberían seleccionar suplementos que tengan más de $100 \%$ a $150 \%$ del valor diario para cada vitamina.
Tabla 3. Etiqueta típica de un multivitamínico.

\begin{tabular}{|c|c|c|}
\hline \multicolumn{3}{|c|}{$\begin{array}{c}\text { Datos del suplemento } \\
\text { Tamaño de la porción: } 1 \text { tableta }\end{array}$} \\
\hline Cada tableta contiene & $\begin{array}{l}\text { Cantidad por } \\
\text { porción }\end{array}$ & $\%$ VD \\
\hline Vitamina A ( $20 \%$ beta-caroteno) & $5,000 \mathrm{IU}$ & $100 \%$ \\
\hline Vitamina C & $60 \mathrm{mg}$ & $100 \%$ \\
\hline Vitamina D & $400 \mathrm{IU}$ & $100 \%$ \\
\hline Vitamina E & $30 \mathrm{IU}$ & $31 \%$ \\
\hline Vitamina $\mathrm{K}$ & $25 \mathrm{mg}$ & $100 \%$ \\
\hline Tiamina & $1.5 \mathrm{mg}$ & $100 \%$ \\
\hline Riboflavina & $1.7 \mathrm{mg}$ & $100 \%$ \\
\hline Niacina & $20 \mathrm{mg}$ & $100 \%$ \\
\hline Vitamina $B_{6}$ & $2 \mathrm{mg}$ & $100 \%$ \\
\hline Ácido fólico & $400 \mathrm{mcg}$ & $100 \%$ \\
\hline Vitamina $\mathrm{B}_{12}$ & $6 \mathrm{mcg}$ & $100 \%$ \\
\hline Biotina & $30 \mathrm{mcg}$ & $100 \%$ \\
\hline Ácido pantoténico & $10 \mathrm{mcg}$ & $100 \%$ \\
\hline
\end{tabular}

El agente de Ciencias de la Familia y del Consumidor en su oficina de extensión de su condado puede tener mayor información y clases de nutrición para que usted asista. También un dietista registrado (RD) puede proporcionarle información confiable.

Información nutricional confiable puede ser encontrada en los siguientes sitios del Internet:

http://fycs.ifas.ufl.edu

http://ChooseMyPlate.gov

http://www.nal.usda.gov/fnic

http://www.nutrition.gov 